\title{
A Preliminary Taxonomic Survey of Liverworts in the Nuwara Eliya District (Central Province) of Sri Lanka
}

\author{
Kariyawasam I.U. \\ Department of Botany, University of Sri Jayewardenepura, Sri Lanka \\ isurufasi@gmail.com
}

\begin{abstract}
Bryophytes comprise three distinct lineages: liverworts (Phylum Marchantiophyta), Mosses (Phylum Bryophyta) and hornworts (Phylum Anthocerotophyta). Liverworts are considered to be one of the earliest groups of land plants (embryophytes) and exhibit two main morphological forms; thalloid liverworts and foliose (leafy) liverworts.

Together with the Western Ghats of India Sri Lanka makes a biodiversity hotspot. Sri Lanka has a rich biodiversity of cryptogams including bryophytes. Climatic conditions and topographic variation in the Nuwara Eliya district, located in the central hilly area of the country, provide ideal habitats for the growth of bryophytes. The main aim of the study is to provide a preliminary floristic inventory of the liverwort flora of the area surveyed. Liverworts were collected during both monsoon and inter-monsoon seasons over a period of one year from different habitats using standard collection methods. Collected liverwort specimens were observed for key morphological and anatomical characters and voucher herbarium specimens were prepared for further studies.

Specimens were identified to species or genus level using the available taxonomic literature. A total of 40 liverwort specimens were collected from different habitats and of these 12 were assigned to complex thalloid genera or species, 12 to simple thalloid taxa and 16 to foliose (leafy) taxa. Taxonomic descriptions elaborating on the key characteristic features were prepared for the genera and species collected. Taxonomic keys were prepared to separate taxa. Further intensive field work and systematic surveys are needed to compile a complete systematic report. This will open a novel avenue for the systematics and conservation of bryoflora in Sri Lanka.
\end{abstract}

Keywords: Bryophytes, Liverworts, Preliminary survey, Nuwara Eliya District, Sri Lanka

Proceedings of the International Forestry and Environment Symposium 2016, Department of Forestry and Environmental Science, University of Sri Jayewardenepura, Sri Lanka. 